\title{
Individual device active cooling for enhanced system- level power density and more uniform temperature distribution
}

\author{
Y. Zeng, A. Hussein, A. Castellazzi \\ Power Electronics Machines and Control Group \\ Nottingham University \\ Nottingham, United Kingdom \\ eeyyqz@nottingham.ac.uk; alberto.castellazzi@nottingham.ac.uk
}

\begin{abstract}
This paper provides a method of individual device active cooling system to balance the temperature distribution of system-level power density. 3L-ANPC GaN inverter was used to test and prove the feasibility of it in using multi-level systems.
\end{abstract}

Keywords-Individual active cooling system, GaN HEMT, $3 L$ ANPC inverter

\section{INTRODUCTION}

Progress in semiconductor device technology evolution has not been matched by corresponding advancements in packaging, passives and cooling. The result is that system integration levels and performance optimization (efficiency and reliability) cannot quite realize the full potential offered by the active device technology and characteristics in terms of heat-generation rate and temperature withstand capability. The issue is particularly sensitive in the case of wide-band-gap devices ( $\mathrm{SiC}, \mathrm{GaN}$ ), which find great favor in the implementation of multi-level inverter topologies, in which non-uniform power dissipation conditions among the chips are common. While bespoke packaging solutions are being looked at and filter size reduction is made possible by higher switching frequencies, deeper studies into cooling options are still wanting. This paper presents an original approach, based on the replacement of a common multichip cooler with an individual one, to yield: flexible cooling parameter setting based on individual chip dissipation; elimination of thermal cross-coupling effects; reduced overall volume.

\section{CHARACTERISTICS OF THE SYSTEM}

\subsection{Individual coolers}

As a case study, reference is made to a $2 \mathrm{~kW} 3$-level GaN inverter intended for photo-voltaic applications [1]. The inverter uses $6 \times 600 \mathrm{~V}$ rated transistors, in TO220 discrete package shown in Fig.1; its power density is mainly determined by input/output filter elements and heatsink, which is shared by all devices, according to common thermal management design practice. In this work we replaced the single heat-sink with individual ones for each transistor (Fig.2): the design involves the use of a square ceramic heatsink interposed between device and fan. The HEMT is mounted onto the heatsink by a built-in bi-adhesive tape. The fan with the same as size as the heatsink is mounted onto the ceramic heatsink using adhesive tape wound around, so that no drilling or other mechanical work is needed. It is very compact and easy to mount solution.

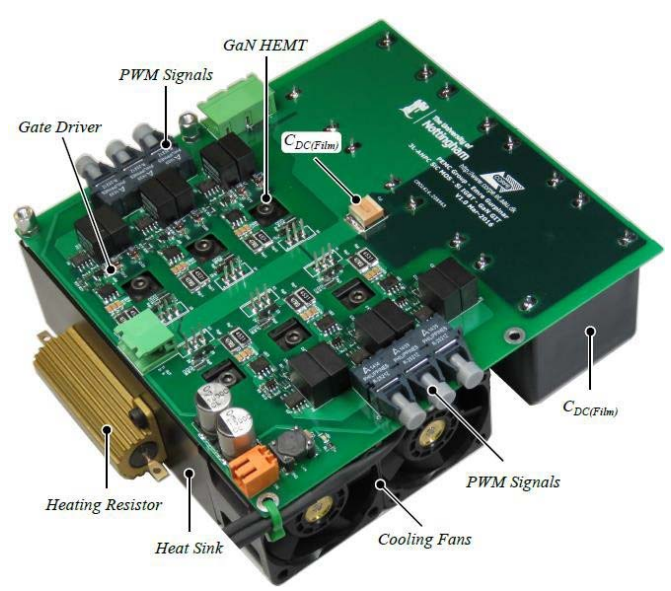

Fig. 1: 3-Level ANPC inverter assembly with indication of functional parts.
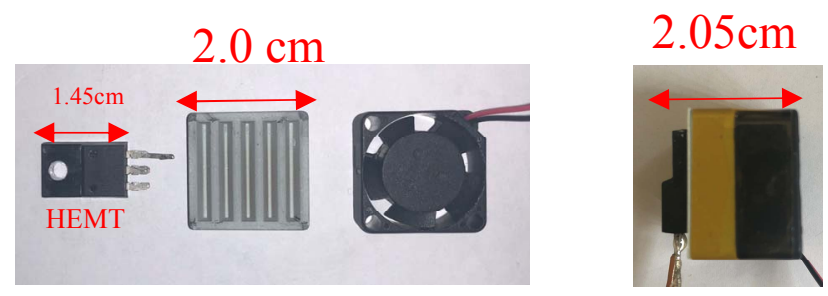

Fig. 2: Individual transistor cooling approach pursued in this study: transistor mounted on ceramic heatsink, mounted on mini-fan.

The Parameters of ceramic heatsink and fans are summarized in Table I. It is clear that the whole volume and weight significantly decrease. 
TABLE I. HEAT-SINK AND FAN PARAMETERS

\begin{tabular}{cl}
\hline Ceramic Heatsink & \multicolumn{1}{c}{ Fan } \\
& Rated Voltage $=5 \mathrm{~V}$ \\
Weight $<8.784 \mathrm{~g}$ & Rated Current $=135 \mathrm{~mA}$ \\
Thermal Conductivity & Operating range $=2.5-6 \mathrm{VDC}$ \\
$=41-50 \mathrm{~W} / \mathrm{m} . \mathrm{k}$. & Operating Temp. $=-10-70 \mathrm{deg}$ \\
& $\begin{array}{l}\text { Air flow }=1.6 \mathrm{CFM} \\
\text { Weight }=4.64 \mathrm{~g}\end{array}$ \\
& Acoustic Noise $=23.0 \mathrm{~dB}(\mathrm{~A})$ \\
\hline
\end{tabular}

Fig. 3 shows the 3L-ANPC inverter after mounting with individual coolers

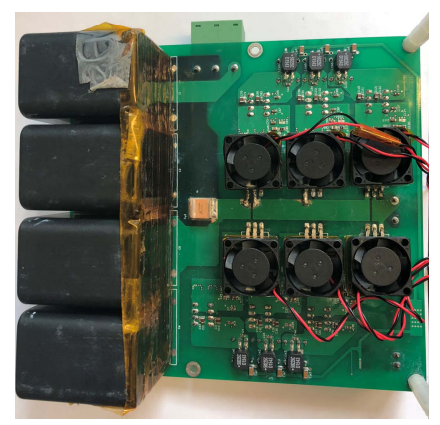

Fig. 3 The back view of 3L-ANPC inverter after mounting with new coolers.

\subsection{Thermal analysis}

The thermal network for one of devices of this ANPC inverter are illustrated in Fig. 4 where $T_{j}$ is junction temperature, $T_{h}$ is heat sink temperature, $\mathrm{T}_{\mathrm{a}}$ is room temperature $\left(22^{\circ} \mathrm{C}\right), \mathrm{P}_{-}$loss is power loss across a single device, $\mathrm{R}_{\mathrm{jc}}$ is junction-to-case thermal resistance, $R_{c h}$ is case-to-heat sink thermal resistance and $R_{h r}$ is required thermal resistance of the heatsink. $R_{f a n}$ is the thermal resistance of fan. $\mathrm{X}$ represents one of six switches. Table 2 shows known parameters of this model.

\subsection{Control method of $3 L-A N P C$ inverter}

The topology of the above $3 \mathrm{~L}-\mathrm{ANPC}$ GaN inverter is shown in Fig. 5
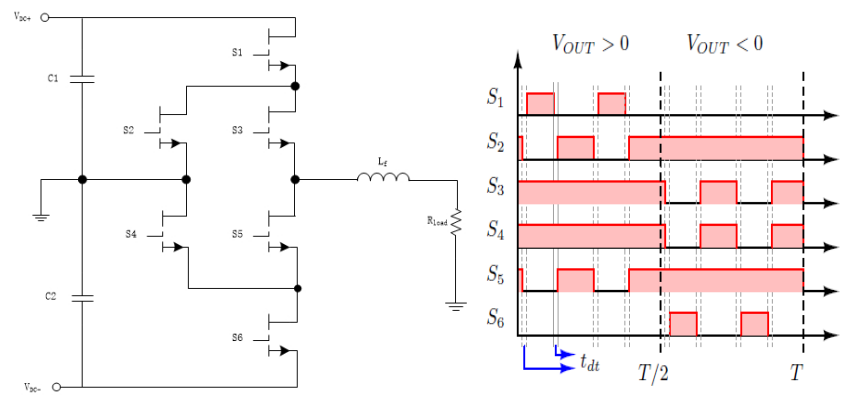

Fig. 5 The topology of 3L-ANPC GaN inverter (left); PWM control method in this case study [2] (right).

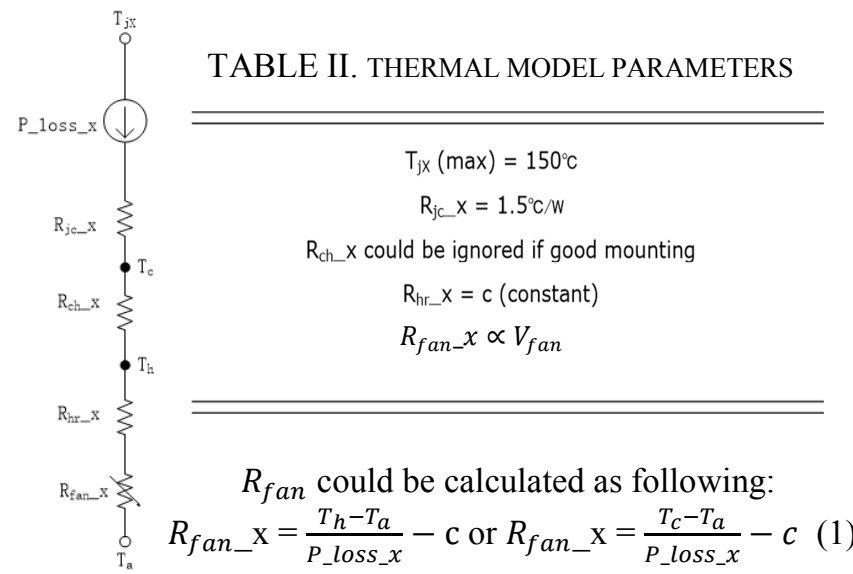

Fig. 4 The thermal model for individual device of 3L-ANPC inverter

Because GaN HEMT has capability of reverse conduction, no parallel diodes needed. One PWM control method described in [2] was used to control this 3L-ANPC inverter. Synchronous rectification applied to decrease the conduction loss. The PWM sequence is shown in Fig. 6.

\section{EXPERIMENTAL RESULTS AND DISCUSSIONS}

The aim of the experiment is to prove that this individual cooler is able to balance the temperature without at the expense of volume and weight.

\subsection{Thermal resistance of the fan}

The case temperature at the steady state of GaN HEMT was measured by thermal couple during the experiment and thermal resistance of fan could be calculated using equation (1). The measured temperature and thermal resistance are summarized in Table 3.

\section{TABLE III. MEASURED TEMPERATURES}

\begin{tabular}{cccccc}
\hline P_loss $(\mathrm{W})$ & No fan & $3 \mathrm{~V}$ & $4.5 \mathrm{~V}$ & $5 \mathrm{~V}$ & $6 \mathrm{~V}$ \\
0.05 & 25.6 & 24.8 & 24.6 & 24.6 & 24.7 \\
0.3 & 27.1 & 26.3 & 26.2 & 26.2 & 26.1 \\
0.6 & 30.2 & 28.6 & 28.2 & 28.1 & 28 \\
1.2 & 35.3 & 32.4 & 31.6 & 31.4 & 31.2 \\
2 & 44.4 & 38.5 & 36.5 & 36.4 & 35.6 \\
2.7 & & 45.5 & 42.1 & 42 & 41.4 \\
3.85 & & 55.6 & 51.3 & 50.2 & 49.2 \\
5.2 & & 66.2 & 61.3 & 60.6 & 59.1 \\
\hline
\end{tabular}

When power loss is greater than $2 \mathrm{~W}$, the temperature will increase dramatically, the device will face with more possibility of breaking down. Therefore, if only heatsink works, we stopped at when the power loss is $2 \mathrm{~W}$. It should also be noted that the case temperature varies a lot at low power. Also, fig. 7 shows the temperature changes due to the power loss under different biased voltage of the fan. 
Case Temperatures of GaN HEMT under different fan voltages

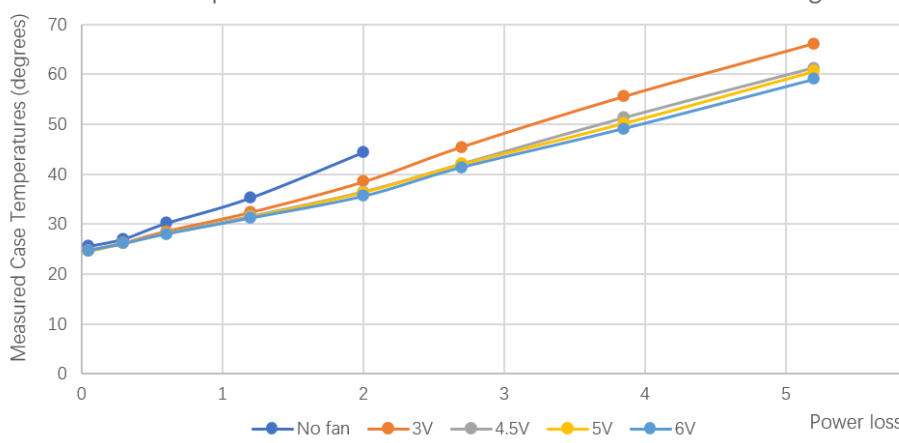

Fig. 7 The trend of the change of case temperatures due to power loss

From the above figure, these trends could be linearly interpolated. The interpolated equations are summarized in Table 4.

TABLE IV. INTERPOLATED EQUATIONS

\begin{tabular}{cc}
\hline \hline Fan Voltage (V) & \multicolumn{1}{c}{ Equations } \\
No fan (OV) & $9.6944 x+24.474$ \\
3 & $8.1682 x+23.503$ \\
4.5 & $7.125 x+23.564$ \\
5 & $6.6592 x+23.677$ \\
6 & $6.6592 x+23.677$ \\
\hline
\end{tabular}

When fan voltage is $5 \mathrm{~V}$ or $6 \mathrm{~V}$, the interpolated equations are the same because the air flow (speed of the fan) are almost the same even if the biased voltage increases. However, the measured case temperature shows the possibility of decreasing by at least $0.5^{\circ} \mathrm{C}$ when increasing the biased voltage to $5 \mathrm{~V}$ to $6 \mathrm{~V}$ if the power loss is greater than $2 \mathrm{~W}$.

The thermal resistance could be calculated using Table 3 and equation (1). Assume $\mathrm{R}_{\mathrm{hr}}$ is a small value, by approximately calculating the surface area of the heatsink, and apply equation

$R_{h r}=\frac{L}{\sigma A}(2)$, where $\sigma$ is thermal conductivity, the value of $R_{h r}$ is $0.35^{\circ} \mathrm{C} / \mathrm{W}$. Therefore, thermal resistances of the fan are summarized in Table 5 and the curve (Fig. 8) based on this shows the trend of change

TABLE V. FAN THERMAL RESISTANCE

\begin{tabular}{cccccc}
\hline \hline P_loss $(\mathrm{W})$ & No fan & $3 \mathrm{~V}$ & $4.5 \mathrm{~V}$ & $5 \mathrm{~V}$ & $6 \mathrm{~V}$ \\
& 72 & 55.65 & 51.65 & 51.65 & 53.65 \\
0.05 & 17 & 13.98 & 13.65 & 13.65 & 13.32 \\
0.3 & 13.67 & 10.65 & 9.98 & 9.82 & 9.65 \\
0.6 & 11.08 & 8.32 & 7.65 & 7.48 & 7.32 \\
1.2 & 11.2 & 7.90 & 6.90 & 6.85 & 6.45 \\
2 & & 8.35 & 7.09 & 7.06 & 6.84 \\
2.7 & & 8.37 & 7.26 & 6.97 & 6.71 \\
3.85 & & 8.15 & 7.21 & 7.07 & 6.78 \\
5.2 & & & & & \\
\hline
\end{tabular}

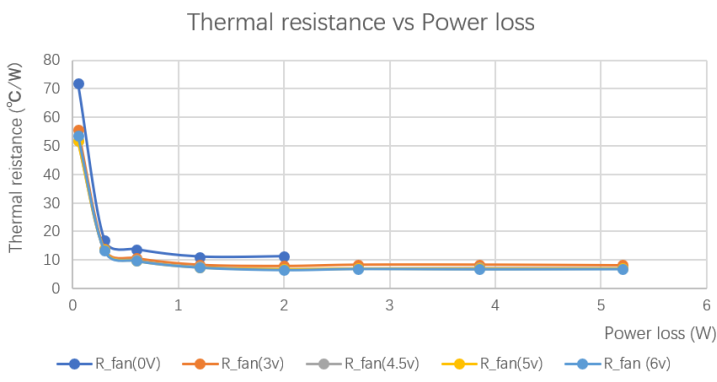

Fig. 8 Thermal resistances changes with fan voltage

It is clear that the thermal resistance decreases with the increase of the fan voltage. At low power, the temperature measurement might cause more error in calculating the thermal resistance which explain the significant thermal resistance at low power. When power loss is greater $2 \mathrm{~W}$, the value of fan thermal resistance is more accurate.

Also, the thermal resistance of fan does not change remarkably due to the limitation of the fan when increase the voltage which affect the effectiveness of this individual cooler.

\subsection{Case study}

The power loss of each device in this 3L-ANPC inverter was simulated using Plecs. Simulation parameters are summarized in Table 6.

\section{TABLE VI. SIMULATION PARAMETERS}

\begin{tabular}{lc}
\hline DC link Voltage (V) & 700 \\
Output RMS Voltages(V) & 220 \\
Output Power (W) & $1 \mathrm{~K}, 1.25 \mathrm{~K}, 1.5 \mathrm{~K}$ \\
Carrier Frequency (KHz) & 100 \\
Output Filter Inductance (mH) & 1.6 \\
Dead time (ns) & 500 \\
Modulation Index & 0.95 \\
\hline
\end{tabular}

Simulation results were illustrated in Table 7. Due to the symmetry of ANPC inverter, only power loss of the upper side switches loss.

\section{TABLE VII. POWER LOSS OF HIGH-SIDE DEVICES}

\begin{tabular}{cccc}
\hline \multirow{2}{*}{ Output Power (W) } & \multicolumn{4}{c}{ Power loss on each device (W) } \\
& S1 & S2 & S3 \\
1000 & 1.67 & 1.61 & 2.15 \\
1250 & 2.43 & 1.99 & 2.92 \\
1500 & 3.28 & 2.48 & 3.9 \\
\hline
\end{tabular}

From Table 7, S3 and S5 are the most stressed by power loss.

Therefore, we attempt to control the temperature of S3 by changing the fan voltage to make it more balanced. Under normal condition, we used rated $5 \mathrm{~V}$. At this time, the corresponding temperature of $\mathrm{S} 3$ could be interpolated using the equation in Table 4. To balance the temperature, we could turn off the fan when $\mathrm{P}$ loss is $2.15 \mathrm{~W}$ use $3 \mathrm{~V}$ when $\mathrm{P}$ loss is $2.92 \mathrm{~W}$ and use $6 \mathrm{~V}$. The results could be seen in Table 8 and Fig. 9. 
TABLE VIII. CASE TEMP. FOR 5V FAN BIAS

\begin{tabular}{ccc}
\hline & \multicolumn{2}{c}{ Case Temperature (degrees) } \\
Rower Loss (W) & Rated Voltage 5V & Varied fan voltage \\
2.15 & 38 & $45(0 \mathrm{~V})$ \\
2.92 & 43 & $47(3 \mathrm{~V})$ \\
3.9 & 50 & $49(6 \mathrm{~V})$ \\
\hline
\end{tabular}

Temperature changes with the power loss under different conditions

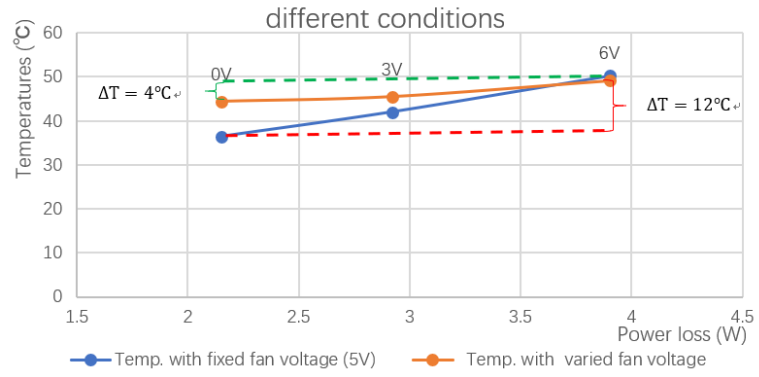

Fig. 9 The case temperatures when keeping the rated voltage and changing the fan voltage

It is clear that the temperature difference when the power loss increase from $2.15 \mathrm{~W}$ to $3.9 \mathrm{~W}$ decrease $8^{\circ} \mathrm{C}$ using varying fan voltage method rather than keeping at $5 \mathrm{~V}$.

Furthermore, we could balance the temperatures between two devices. From Table 7, the power loss difference between S2 and $\mathrm{S} 3$ are the maximum. (Fig. 10)

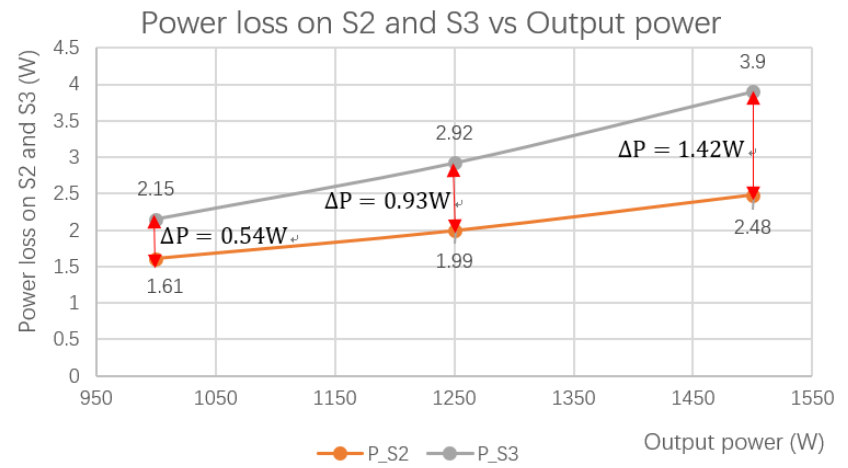

Fig. 10 Power loss and its difference between S2 and S3

The case temperatures for both $\mathrm{S} 2$ and $\mathrm{S} 3$ could be interpolated using equations in Table 4. Assume the constant fan voltage (5V). The temperatures for fixed fan voltage are summarized in Table 9. Then control the temperature by adjusting the fan voltage, the results are summarized in Table 10.

TABLE IX. CASE TEMPERATURE OF S2 AND S3 AT 5V FAN BIAS

\begin{tabular}{cccc}
\hline & \multicolumn{3}{c}{ Case Temperature (degrees) } \\
Power Loss (W) & S3 & S2 & Difference \\
2.15 & 38 & 34 & 4 \\
2.92 & 43 & 37 & 6 \\
3.9 & 50 & 40 & 10 \\
\hline
\end{tabular}

From Table 9, the temperature difference will increase with the power loss increase.

\begin{tabular}{cccc} 
TABLE X. CASE TEMPERATURE OF S2 AND S3 WITH REGULATED \\
FAN BIAS \\
\hline \multicolumn{4}{c}{ Case Temperature (degrees) } \\
Power Loss (W) & S3 & S2 & Difference \\
2.15 & $38(5 \mathrm{~V})$ & $37(3 \mathrm{~V})$ & 1 \\
2.92 & $43(5 \mathrm{~V})$ & $44(0 \mathrm{~V})$ & 1 \\
3.9 & $49(6 \mathrm{~V})$ & $48(0 \mathrm{~V})$ & 1 \\
\hline
\end{tabular}

Table 10 shows the possibility that the time difference could be the same even the power loss increases.

\section{CONCLUSION}

These individual active cooling systems have capability of balancing the temperatures of the fan when increasing or decreasing the power loss of each device. Also, the noise of the system is acceptable. However, the effectiveness is restricted by the characteristics of the fan and the ceramic heatsink. Firstly, the speed of the fan does not change significantly when we increase the biased voltage which causes the small change of thermal resistances. This kind of small fan is the minority number of fan which are available and suitable for this case study in the market even though they have some disadvantages.

Secondly, there are some limitations of the ceramic heatsink. We expect heatsinks with higher thermal conductivity (smaller thermal resistivity) and as the similar size as the device itself. The heat conductivity of ceramic material is worse than metal but it has the advantage of light weight lower thermal expansion coefficient. To improve the feasibility of the individual coolers, new material heatsink could be attempted.

Thirdly, the mounting method, in the case study, the ceramic heatsink has built-in thermal tape and we could use it to mount HEMT onto the heatsink. In the case study illustrated above, we were faced with a problem of not good stickiness for one or two heatsinks, which fell off during the experiment. This proves using thermal tape is not perfect. Furthermore, for the heatsink we used in the experiment, although it is very thin, it has very high thermal resistance which will decrease the effectiveness of The heatsink. To improve this, new method of mounting should be used.

\section{REFERENCES}

[1] E. Gurpinar, A. Castellazzi, 600 V normally-off p-gate GaN HEMT based 3-level inverter, in Proc. 2017 IEEE 3rd International Future Energy Electronics Conference and ECCE Asia (IFEEC 2017 - ECCE Asia), Kaohsiung, Taiwan, 3-7 June 2017.

[2] E. Gurpinar, A. Castellazzi, Trade-off Study of Heat Sink and Output Filter Volume in a GaN HEMT Based Single Phase Inverter, IEEE Transactions on Power Electronics, July 2017 
